\title{
DISCURSOS PEDAGÓGICOS EM "NUVENS": OLHARES AO TRABALHO DOCENTE NA EDUCAÇÃO SUPERIOR COM O ENSINO REMOTO EMERGENCIAL (ERE)
}

\author{
Alan Silus* \\ Angelita Leal de Castro Fonseca** \\ Djanires Lageano Neto de Jesus***
}

RESUMO: A Pandemia da COVID-19 vem provocando grandes transformações na sociedade mundial e com ela várias medidas para conter o contágio estão sendo adotadas, uma delas é o isolamento social, com restrições e fechamento provisório de espaços das Instituições de Ensino Superior (IES). A remotividade do ensino e aprendizagem vem ganhando espaço com a utilização das Tecnologias Digitais de Informação e Comunicação (TDICs) e emergencialmente professores e estudantes vão se adaptando na medida do possível. Nesse sentido, o objetivo deste artigo é apresentar alguns discursos pedagógicos a partir dos olhares dos professores da educação superior durante a realização do Ensino Remoto Emergencial (ERE). Para fundamentar nosso texto utilizamos de autores como Bardin (2016), Bakhtin (2012), Charaudeau (2016), Charlot (2013a/2013b), Maingueneau (2010/2015), Marques (2015), Moran (2004), Pimenta \& Anaastasiou (2014), Vasconcelos (2000/2019) e Volóchinov (2017). Como metodologia, trata-se de uma abordagem qualitativa, descritiva, bibliográfica, documental e exploratória, buscando ancorar as respostas dos entrevistados com a utilização de um recurso virtual denominado "nuvem de palavras" para posteriormente aplicação da análise do discurso e conteúdo. Os resultados, baseados nas 506 pessoas entrevistadas, no período de junho a agosto de 2020, apontam desafios impostos aos professores nativos do ensino presencial e que enfrentam os desafios da adaptabilidade do uso das tecnologias educacionais, para fomentar discussões e alternativas híbridas de ensino e aprendizagem.

\begin{abstract}
The COVID-19 Pandemic has been causing great changes in the world society and with it several measures are being taken to contain contagion, one of which is social isolation, with restrictions and provisional closure of spaces of Higher Education Institutions (HEIs). The remotivity of teaching and learning has been gaining ground with the use of Digital Technologies of Information and Communication (TDICs) and emergently teachers and students are adapting as far as possible. In this sense, the objective of this article is to present some pedagogical speeches from the perspective of higher education teachers during the realization of Emergency Remote Education (ERE). To support our text, we used authors such as Bardin (2016), Bakhtin (2012), Charaudeau (2016), Charlot (2013a /2013b), Maingueneau (2010/2015), Marques (2015), Moran (2004), Pimenta \& Anaastasiou (2014), Vasconcelos (2000/2019) and Volóchinov (2017). As a methodology, it is a qualitative, descriptive, bibliographic, documentary and exploratory approach, seeking to anchor the respondents' responses with the use of a virtual resource called "word cloud" for later application of discourse and content analysis. The results, based on the 509 people interviewed, from June to August 2020, point out challenges imposed on native teachers of classroom teaching and who face the challenges of adaptability in the use of educational technologies, to foster discussions and hybrid teaching and learning alternatives .
\end{abstract}

PALAVRAS-CHAVE: Ensino Remoto Emergencial; Ensino Superior; Nuvens de Palavras; Discurso Pedagógico

KEYWORDS: Emergency Remote Teaching; University Education; Word Clouds; Pedagogical Speech. 
INTRODUÇÃO

A Pandemia do novo Coronavírus (COVID-19) modificou a forma de comunicação no mundo, para mitigar as contaminações, escolas e Universidades foram fechadas e o ensino passou a ser ofertado por meio de Ambientes Virtuais de Aprendizagem (AVA), de escolha das instituições de ensino. As salas de aulas, foram substituídas por salas virtuais e tanto docentes como estudantes precisaram se reinventar do dia para noite.

No Ensino Superior, na modalidade presencial, a suspensão das aulas presenciais ocorreu pela Portaria do Ministério da Educação (MEC) no 343 de 18 de Março de 2020, onde nela havia a autorização por trinta dias do oferecimento de aula remotas, mas os contágios de COVID-19 se alastraram por todo Brasil e a determinação oficial foi substituída pela Portaria $n^{a} 544$, em que o MEC autoriza que as aulas presenciais sejam substituídas por aulas em meios digitais, enquanto durar a situação de Pandemia (BRASIL, 2020).

O efeito das suspensões das aulas presenciais no Ensino Superior Brasileiro, desencadeou alguns motes emergenciais, que eram discutidos por determinadas Instituições de Ensino Superior (IES) e, em outras não, tais como: As IES possuem estrutura tecnológica para implementação do AVA? Os docentes estão preparados para ministrar aulas em meios digitais? As Tecnologias Digitais de Informação e Comunicação (TDICs) são uma realidade nas IES? Nesse sentido, o objetivo deste artigo é apresentar alguns discursos pedagógicos a partir dos olhares dos professores da educação superior durante a realização do Ensino Remoto Emergencial (ERE).

Segundo dados da Organização das Nações Unidas para a Educação, a Ciência e a Cultura (UNESCO, 2020), mais de 1,5 bilhão de estudantes de 191 países estão sendo afetados pelo fechamento das escolas e Universidades com o cenário pandêmico. Com isso, as organizações envolvidas com a educação, tanto públicas como privadas vêm buscando formas para promover o equilíbrio no relacionamento entre professores e estudantes, a mediação no uso excessivo da tecnologia como ferramenta de comunicação para o ensino e aprendizagem, bem como a atenção sobre as dificuldades ao uso das TDICs que envolvem docentes, discentes, famílias e sociedade como um todo.

De acordo com o Instituto Nacional de Estudos e Pesquisas Educacionais Anísio Teixeira (INEP) com o último censo publicado da educação superior brasileira em 2019, referente ao ano anterior, são 384.474 docentes atuando, sendo 173.868 das IES públicas e 210.606 das IES privadas (BRASIL, 2019). Com esse cenário expressivo, professores e gestores educacionais tiveram que adaptar de maneira emergencial, incluindo seus planos de atividades, metodologias e conteúdos de forma geral, passando ainda da modalidade presencial para o ERE, totalmente experimental. 
A urgência de implementação do ERE, vem provocando uma mudança de comportamento dos gestores das IES brasileiras, sobretudo nas fragilidades de operação do uso das TDICs, já que muitos estudantes e professores dos cursos de graduação e pós-graduação não estavam preparados e possuíam baixo letramento digital. Para Antunes et al. (2020) esses recursos tem se mostrado em crescimento global, direcionando as IES a reformular além de suas práticas pedagógicas, suas ferramentas tecnológicas de ensino, construindo programas, redes e mídias que permitam a integração dos estudantes com professores em redes de aprendizagem em AVA, dando continuidade do sistema utilizado pelo Ensino Superior presencial, mesmo no isolamento social.

Como metodologia, trata-se de uma abordagem qualitativa, descritiva, bibliográfica, documental e exploratória, buscando ancorar as respostas dos entrevistados com a utilização de um recurso virtual denominado "nuvem de palavras" para posteriormente aplicação da análise do discurso e conteúdo. O corpus da pesquisa é composto pela amostra de docentes do Ensino Superior brasileiro, nas diferentes áreas de conhecimento, que estão realizando o ERE, durante a Pandemia da COVID-19, mais precisamente com recorte temporal entre os meses de junho a agosto de 2020.

Os entrevistados foram contatados por mensagem enviada por meio do correio eletrônico, enviada para suas respectivas caixas de mensagens, a partir da coleta de dados via websites oficiais das IES credenciadas pelo INEP. Além disso, os pesquisadores utilizaram também suas redes sociais WhatsApp e Instagram, para o envio de convites para participar da pesquisa.

Foram enviados um total de 1200 links com o questionário. O intervalo de envio e coleta das informações compreendeu de 05 de junho a 30 de agosto de 2020. Desse total de enviados, obtivemos retorno de 509 respostas, o que possibilitou uma taxa de retorno de $42 \%$, que confrontado tal resultado com a pesquisa realizada por Dias; Anjos \& Rodrigues (2019) que utilizaram a pesquisa com o envio de questionários pela internet, cujo resultado foi de 34,8\%, obtivemos um retorno acima da média, ou seja, satisfatória. Do total de questionário respondidos foram utilizados como análise 506, já que 3 respondentes após a leitura do Termo de Consentimento Livre e esclarecido (TCLE) optaram por não participar.

Nesse sentido, o presente artigo ficou dividido em três partes: a primeira contextualizando o trabalho docente e as tecnologias no processo de ensino e aprendizagem no Ensino Superior a partir de um breve recorte teórico acerca da TDICs e do ERE na segunda parte buscamos apresentar questões sobre discursos pedagógicos e tensionamentos pandêmicos como forma de justificar o trabalho da pesquisa e, por fim, no percurso metodológico, foram apresentados os resultados da pesquisa nacional, de acordo com o recorte temporal, que corroboram com os objetivos de apresentar em nuvens de palavras os discursos digitais e representações dos professores do Ensino Superior brasileiro na Pandemia. 


\section{O TRABALHO DOCENTE E AS TECNOLOGIAS NO PROCESSO DE ENSINO E APRENDIZAGEM NO ENSINO SUPERIOR}

Há algum tempo as tecnologias de informação vem ganhando força no segmento do ensino, e principalmente nestes últimos anos elas passaram a compor a vida escolar em diversos níveis, indo do ensino básico ao Ensino Superior e níveis acadêmicos mais avançados. Com a chegada do Novo Coronavírus, as tecnologias de informação se tornaram essenciais.

É com essas tecnologias e por meio dela, que escolas e Universidades estão mantendo seu calendário acadêmicos e oferecendo a continuidade do ensino pelo mundo. Contudo as Tecnologias da Informação e da Comunicação (TICs), tiveram início anos 60 e 70 e surgiram para modificar a interação e comunicação das pessoas pelo mundo, trazendo não somente uma mudança social, mas também anunciando como o acesso ao conhecimento se transformaria (DOMINICK; ALVES, 2018).

Nos últimos anos o mundo virou digital e a acessibilidade às tecnologias digitais passaram a ser utilizadas em escalas exponenciais e as TICs, passaram a ser denominadas Tecnologias Digitais de Informação e Comunicação (TDICs). Entre tanto, o uso das TDICs não pode estar desconectada de um bom direcionamento pedagógico, Silva em 2011, já discutia sobre a necessidade implementação de políticas públicas no Brasil para acelerar o processo de inclusão digital nas escolas, que incluíam ações como: melhorar a qualidade do processo de ensino-aprendizagem por meio das TDICs; promover uma educação científica e tecnológica e possibilitar a criação de um ecossistema de inovação por meio das tecnologias. Tais ações em muitas escolas e Universidade brasileiras vinham sendo implementadas, mas as políticas principalmente nas IES com cursos na modalidade presencial, ainda estavam longe de chegar ao que estamos vivendo hoje, uma educação totalmente digital.

Segundo Moreira; Henriques \& Barros (2020) ninguém estava preparado para ingressar tão rápido ao ambiente on-line, professores e estudantes de forma emergencial passaram a vivenciar o Ensino Remoto de Emergência ou Emergencial (ERE) que transfere as práticas pedagógicas presenciais para AVA, com utilização das TDICs.

O ERE imposto pela Pandemia da COVID-19, levantou a questão das IES e dos professores ministrarem suas aulas no formado EAD, ou seja, Educação a Distância, porém há que se destacar que esta modalidade já consolidada e regularizada por normativas próprias, apenas tem a ligação com o ERE, pelo uso de ensino por meio de tecnologias digitais.

A educação remota refere-se à mudança do espaço físico, que passou da sala de aula para o meio digital, no entanto os professores pouco tinham habilidades para produção, condução e manuseio das ferramentas para o ERE, muitos até mesmo de forma solitária, 
tiveram que aprender a gravar vídeos, realizar videoconferências e produzir materiais pedagogicamente estratégicos para a modalidade online, sejam de formas síncronas ou assíncronas (JOYE; MOREIRA \& ROCHA, 2020).

Segundo Moran (2004) é importante destacar que as tecnologias sozinhas, não transformam o ensino, mas podem ser aliadas com uso de metodologias próprias e estratégias engajadoras de aprendizagem com seu uso:

as tecnologias são só apoio, meios. Mas elas nos permitem realizar atividades de aprendizagem de formas diferentes às de antes. Podemos aprender estando em juntos em lugares distantes, sem precisarmos estar sempre juntos numa sala para que isso aconteça (MORAN, 2004, p. 348).

As metodologias engajadoras, inovadoras e que permitem a ação ativa dos estudantes também são desafios presentes na prática dos docentes do Ensino Superior e com a chegada do ERE, a necessidade de modificar a forma de ensino tradicional ficou evidenciada. Para Revuelta et al (2020) é essencial que os professores sejam criativos e contribuam para a promoção de um ensino-aprendizagem colaborativo, engajando os estudantes em meio a Pandemia da COVID-19.

Segundo a autora e seus colaboradores ao potencializar as TDICs juntamente com práticas didático-pedagógicas engajadoras, os estudantes podem desenvolver a capacidade de solucionar problemas; gerar novas ideias; desenvolver espírito empreendedor; tornar-se autônomo no seu processo de aprendizagem; promover a relação entre alunos e professores e estimular a aprendizagem colaborativa. Destacando-se que o professor é o principal agente deste processo e as tecnologias e metodologias são ferramentas para sua prática docente.

Para Córica (2020) mesmo que as metodologias inovadoras e criativas, possam melhorar o ensino-aprendizagem, e as tecnologias melhorem as comunicações entre estudantes e professores, para alguns professores, os quais preferem os métodos e estilos tradicionais de ensino, tais estratégias podem gerar um conflito entre as instituições de ensino e os professores. Entretanto as IES podem promover formações docentes, e estratégias de mudanças organizacionais que podem conduzir os professores para o inevitável, mudar ou permanecer no campo da incerteza.

De acordo com o autor

em uma sociedade em que as mudanças acontecem cada vez mais rapidamente, elas fazem parte do processo organizacional e ocorrem pela convicção de que é preciso expandir, melhorar e transformar o sistema. Esta mudança, cuja necessidade se manifesta de forma transversal nas instituições de ensino, é ubíqua, contínua e ocorre diariamente, afetando todas as áreas e não apenas as que se relacionam com as tecnologias (CÓRICA, 2020, p. 257, tradução nossa). 
A Pandemia da COVID-19, fez ressurgir algumas discussões já presentes na docência do Ensino Superior, dentre elas a necessidade de mudança no fazer pedagógico, implementações de estratégias de ensino inovadoras e engajadoras e a proficiência dos docentes com as TDICs. Corroborando com este pensamento, Bacich \& Moran (2018) destacam que é um desafio tanto nas esferas públicas como nas privadas, fomentar entre os professores o uso da TDICs, de forma integrada aos currículos.

A utilização dessas tecnologias não é uma ação que ocorre de um dia para outro, para a sua prática ser efetiva são necessários vários processos, que ordenadamente se movimentam para que gradativamente os usuários se tornem proficientes. Tais etapas são divididas da seguinte forma:

- Exposição: contato inicial e exploração dos recursos;

- Adoção: momento em que o professor se sente confortável em utilizar os recursos;

- Adaptação: momento em que o professor passa a utilizar o recurso eficientemente com os alunos;

- Apropriação: momento em que o professor já consegue avaliar os recursos e selecionar o que tenha melhor potencial para sua prática pedagógica;

- Inovação: neste momento a criativa impera e o professor evidencia as TDICs e promove a aprendizagem dos alunos.

O trabalho docente no Ensino Superior frente a COVID-19, tornou-se mais desafiador, fazendo com que os docentes não só se preocupassem com as questões pedagógicas dos conteúdos e conhecimentos acadêmicos, mas também com a intercessão das metodologias e TDICs em seus planejamentos.

Há que se destacar que do início da Pandemia até os dias de hoje, muitas ações já foram desenvolvidas pelas IES, grupos de estudos em tecnologias surgiram, formações para tecnologias educacionais estão na palma da mão dos professores e já estamos mais habituados às telas de computadores e as turmas virtuais. Mas as discussões acerca da prática docente em meio ao ERE necessitam ser muito discutidas ainda.

\section{DISCURSOS PEDAGÓGICOS E TENSIONAMENTOS PANDÊMICOS}

Os tensionamentos acerca da prática docente promove na atualidade uma série de debates sobre o processo de ensino e aprendizagem. Com o agravamento da Pandemia do COVID-19, os discursos sobre a práxis incidem cada vez mais, pois, a unidade do ambiente educacional deixou de ser a sala de aula, dando espaço aos territórios virtuais. 
Para Vasconcelos

A aula, momento de encontro entre professores e alunos, é o espaço privilegiado do processo de ensino-aprendizagem para o qual o professor se preparou. Essa aula foi pensada a partir do conhecimento de um aluno real, com suas particularidades geográficas, sociais e culturais e seus interesses específicos. Esse aluno real fala hoje a linguagem da tecnologia, e é dessa linguagem que o docente deve se aproximar, tirando dela o melhor proveito para atrair a atenção, despertar o interesse e estabelecer o diálogo como canal de aprendizagem (VASCONCELOS, 2019, p. 70).

As práticas pedagógicas cotidianas virtualizaram-se e, junto a elas surge uma diversidade de angústias e anseios por parte dos docentes e discentes. Nos mais diversos contextos educativos, a inserção da cultura digital na vida do alunado abriu espaço para refletirmos sobre o papel da comunicação digital na sociedade (VASCONCELOS, 2019).

Desde os anos 2000 as instituições de ensino vêm organizando-se e adaptando-se aos novos modelos de educação, um desses modelos é o ensino híbrido do qual Vasconcelos o define como o

modelo de educação que se efetiva no ambiente físico escolar, off-line (no qual o educando estuda em grupo e com o professor), e no ambiente virtual, on-line (em que o aluno faz uso de ferramentas tecnológicas digitais). É uma realidade com a qual todos os professores irão se defrontar num curto espaço de tempo e, portanto, é melhor conhecê-la para assim melhor capitalizar seus pontos positivos, em favor de uma aprendizagem significativa. Certo está que tal decisão será institucional e a ela professores e alunos deverão adaptar-se (VASCONCELOS, 2019, p. 70).

O ensino híbrido consolidou-se no Ensino Superior pela sua ação semipresencial, possibilitando um processo de aprendizagem em que a presença do professor em sala é frequente, porém, o uso das mais diversas tecnologias e ambientes virtuais de aprendizagem promovem entre os sujeitos deste processo a construção de uma comunidade de práticas.

Dessa forma, ouvir os professores sobre quais as suas inquietações e desejos para com a sala de aula neste período de isolamento e fechamento de instituições externam que "um dado ato de linguagem pressupõe que nos interroguemos a seu respeito sobre as diferentes leituras que ele é suscetível de sugerir" (CHARAUDEAU, 2016, p. 17). Os dados a serem obtidos a partir das instâncias de enunciação dos locutores, promoverão incomensuráveis fontes para a constituição de corpora para análise de discursos e conteúdo.

Nesse sentido, denotamos que, de acordo com Maingueneau (2010, p. 199) "as teorias da enunciação linguística reservam um lugar essencial a reflexividade da atividade discursiva, e em particular às coordenadas que cada ato de enunciação implica: coordenadas pessoais, espaciais e temporais". Ao pensar em pessoas, referimo-nos aos 
sujeitos da pesquisa, em seguida temos os espaços, territórios de fala desses sujeitos que em situação pandêmica constitui-se dos ambientes virtuais e quanto ao tempo, ao tratarmos de uma abordagem digital, este pode ser apenas delimitado como síncrono e assíncrono.

Com a Pandemia do COVID-19 algumas tensões surgiram e foram elucidadas pelos professores como o baixo ou nenhum acesso à internet por parte dos alunos, a pouca aderência a nova configuração de ensino (apresentado por nós como ERE) e as relações socioculturais trazidas com o isolamento social.

Essas tensões justificam-se devido o fato de que "o pensamento pedagógico dissimula a importância social da educação por trás de considerações culturais e justifica o papel da educação na realidade social. Trata-se de um processo ideológico, cujo postulado fundamento é a redução do social ao individual" (CHARLOT, 2013a, p. 83). As instâncias individuais ainda sobrepujam as sociais, porque aos poucos tomamos a consciência da cultura colaborativa e da cooperação entre os pares. As instituições educativas, são as que mais sofrem nesse processo de adaptação.

Dessa forma, investigar as formas de atuação do professor nos mais diversos contextos e principalmente em meio às tensões ocasionadas pela Pandemia, nos mostra que

$$
\begin{aligned}
& \text { trabalhar com a educação do educador em exercício, com um enfoque voltado } \\
& \text { para o compromisso desse profissional com o ato de educar cidadãos } \\
& \text { competentes, capacitados a atuar numa sociedade historicamente determinada } \\
& \text { e prontos para nela intervirem, é tarefa difícil e bastante delicada } \\
& \text { (VASCONCELOS, 2000, p. 49). }
\end{aligned}
$$

O processo de apreensão da prática pedagógica pelos docentes sempre ocasionou reflexões multifacetadas e que muitas vezes pouco contribuíram para a relação teoria e prática, tanto criticada por muitos deles. Por isso, o cuidado com o pensamento sobre as metodologias de ensino caracterizou nos últimos 10 anos, um interesse global aos professores e estudiosos sobre educação.

A emergência no processo de formação docente, em especial o do Ensino Superior, mostram-nos conforme Pimenta \& Anastasiou (2014) que este processo deve ser constituído por uma atividade mediadora entre diferentes personagens, concepções teóricas e práticas, tendo como fim a construção e conquista do conhecimento.

A construção de uma ação docente dialógica apresenta outro fator imprescindível ao trabalho do professor, pois, a promoção do diálogo é importante nas práticas sociais entre eles e seus alunos, uma vez que

a vida é dialógica por natureza. Viver significa participar de um diálogo: interrogar, escutar, responder, concordar, etc. Neste diálogo o homem participa todo e com toda sua vida: com os olhos, com os lábios, as mãos, a alma, o 
espírito, com o corpo todo, com as suas ações. Ele se põe todo na palavra, e esta palavra entra no tecido dialógico da existência humana, no simpósio universal (BAKHTIN, 1963 apud CLARK; HOLQUIST, 2008, p. 12).

Para Pimenta \& Anastasiou (2014, p. 100) "o discurso que domina as mídias é de que as instituições educativas têm por tarefa preparar os jovens para o mundo do trabalho, que, entre outras coisas, exige deles novas competências: criar, pensar, propor soluções, conviver em equipe" e nesse sentido, a proposta de uma aula dialógica em que os alunos participaram, bem como utilizar como recurso pedagógico a atividade de seminários promove nesses indivíduos essas novas competências.

Pautados no pensamento de Soares (2017) acreditamos que a Universidade enquanto instituição comprometida com a luta contra as desigualdades tem função e poder de "vitalizar e direcionar", segundo a autora, as forças progressistas e permitir às classes sociais populares a aquisição e o acesso aos conhecimentos e habilidades que promova no aluno sua transformação social.

Encontramos hoje muitos discursos de professores que caminham para a promoção de novos olhares às realidades e práticas sociais cotidianas. Essa preocupação é retratada por Bakhtin (2012) como uma promoção de singularidades no qual segundo ele "o lugar que apenas eu ocupo e onde ajo e o centro, não somente no sentido abstratamente geométrico, mas como o centro emotivo-volitivo concreto responsável pela multiplicidade concreta do mundo" (BAKHTIN, 2012, p. 118).

Dessa singularidade vista pelo docente é que alcançamos dimensões e patamares universais. Essa alteração, recorre a uma nova forma de pensar as práticas socioculturais, geradoras de novos discursos dos quais "não pode haver um interlocutor abstrato, por assim dizer, isolado" (VOLÓCHINOV, 2017, p. 205), porque é a partir das relações com o outro que nos constituímos e constituímos nossa cultura.

Portanto, dar voz aos integrantes do processo de ensino e aprendizagem mostra-nos o quanto as concepções e anseios apresentados, em especial pelos professores, em tempos de Pandemia podem corroborar para a compreensão profícua da atividade docente no Ensino Remoto Emergencial, bem como nos permitem pensar acerca de como o uso consciente das TDICs ajuda em uma maneira mais ágil de compreensão desses questionamentos respondidos por eles.

\section{3 “PROFESSORES NAS NUVENS": DISCURSOS DIGITAIS E REPRESENTAÇÕES}

Com o enaltecimento da Pandemia no novo Coronavírus, uma crescente preocupação quanto às práticas pedagógicas em escolas, institutos de educação e Universidade ascenderam no cenário brasileiro. Enquanto muitos olhares voltam-se à Educação Básica 
do país, faz-se necessário também pensar as práticas pedagógicas em contexto pandêmico.

Nesse sentido, propomos, juntamente a outros pesquisadores de IES de Mato Grosso do Sul um projeto de pesquisa intitulado Professores do Ensino Superior Brasileiro que Estejam Realizando o Ensino Remoto Emergencial Durante à Pandemia do Novo Coronavírus.

A pesquisa que está em andamento tem por objetivo geral investigar o perfil socioemocional e didático pedagógico da atuação docente na educação superior, bem como seus reflexos no processo de ERE durante e pós a Pandemia da COVID-19. E, como alguns objetivos específicos Identificar os impactos sociais da Pandemia sobre a educação brasileira para compreender o contexto aplicado ao universo universitário; Verificar a práxis docente durante a introdução do ERE para estabelecer um comparativo da carga de atividades realizadas de forma síncronas e assíncronas; Analisar competências socioemocionais dos docentes durante e pós Pandemia da COVID-19 para verificar suas influências no ERE; Averiguar a adaptabilidade do uso das tecnologias educacionais pelo docente nativo do ensino presencial para fomentar discussões e alternativas híbridas de ensino e aprendizagem.

A partir desta proposta, foi lançado como Instrumento de Pesquisa um questionário estruturado elaborado com perguntas fechadas e uma questão aberta utilizando o aplicativo via Google Forms, que faz parte do pacote Google Drive, um serviço de armazenamento e sincronização de arquivos. Os participantes da pesquisa receberam convites por e-mail, pelo WhatsApp e pelo Facebook para participação do estudo.

O critério utilizado para a estratificação da amostra foi: a) Docentes brasileiros; b) Docentes brasileiros em nível superior; c) Docentes brasileiros que atuam no Ensino Superior presencial; d) Docentes brasileiros que atuam no Ensino Superior presencial que aderiram ao ERE durante a Pandemia.

Nesse processo, selecionamos três questionamentos que, a partir das respostas dadas, vamos utilizar um recurso virtual para que possamos desenvolver nossas análises denominado nuvem de palavras que para Prais \& Rosa (2017, p. 205) constitui-se de "um programa informático que produz uma nuvem de palavras, organizando-as, em várias cores e tamanhos, com base no número de menções feitas em determinado texto".

Os caminhos dados ao tratamento das nuvens de palavras, dispostas em imagens, mostram a importância da dimensão icônica que se traduz em enunciados verbais e visuais (MAINGUENEAU, 2015), que constituem o trabalho da produção de efeitos de sentido dados a abordagem e análise dos dados. Concordamos com Laurence Bardin, quanto esta nos apresenta que 
a análise de conteúdo se multiplica às aplicações, marca um pouco o passo ao concentrar-se na transposição tecnológica em matéria de inovação metodológica. Mas observa com interesse as temáticas que se fazem no campo alargado da análise de comunicações: lexicometria, enunciação linguística, análise da conversação, documentação e bases de dados, etc. (BARDIN, 2016, p. 31).

De acordo com a pesquisa aplicada, o perfil dos entrevistados são: 54,2\% são compostos por mulheres; $29,6 \%$ com faixa etária de 36 a 45 anos e $29,1 \%$ de 50 a 60 anos predominantemente; sobre o tempo de serviço em sala de aula, $25,7 \%$ possui 25 anos ou mais e em segundo lugar $(18,2 \%)$ entre 20 a 25 anos de serviço; sobre o local de residência os três estados mais representativos foram 35,4\% Mato Grosso do Sul, 14,8\% do Paraná e $13,4 \%$ de São Paulo; sobre o grau de escolaridade $45,8 \%$ possui doutorado, $26,9 \%$ Mestrado e 19,4\% pós-doutorado; sobre a área de formação acadêmica é predominante em 27,1\% em Humanas e em segundo 26,7\% em Ciências Sociais Aplicadas. Sobre o vínculo profissional $52,4 \%$ é oriundo de IES pública e $41,3 \%$ de IES privada; além disso, $66,8 \%$ atua em Universidades e $16 \%$ em centros universitários

Com relação a primeira pergunta, (Qual a sua expectativa de quando voltar as suas aulas presenciais em sua IES?) obtivemos as seguintes respostas apresentadas na nuvem de palavras 01:

Figura 1: Nuvem de Palavras 01

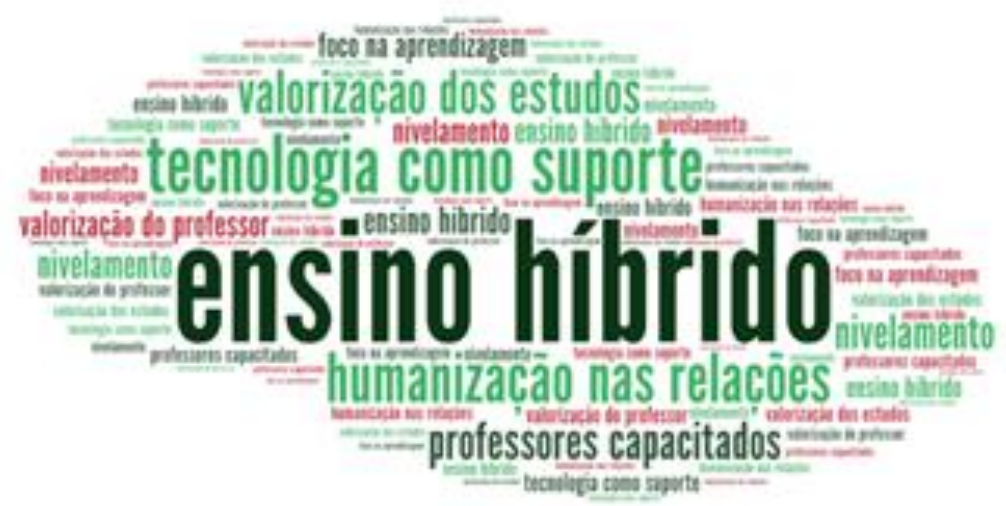

Fonte: Os autores, a partir dos dados da pesquisa.

Na primeira imagem temos em destaque os seguintes termos com a seguinte frequência das respostas dos entrevistados: "ensino híbrido" (285 vezes), "tecnologia como suporte" (223 vezes), humanização nas relações" (174 vezes), "valorização dos estudos" (134 vezes), e "professores capacitados" (104 vezes). Todas essas expectativas apresentadas 
em destaque mostram um novo direcionamento ao pensamento pedagógico dos docentes hoje: eles têm a ciência de que o processo de ensino deverá ser alterado para uma melhor prática, bem como a aproximação social por meio do relacionamento humano também constitui um ponto a ser revisto nas instituições educativas.

Os termos apresentados em evidência pelos docentes mostram que as práticas de ensino

devem voltar-se, para que consigam atender à demanda de um mercado altamente flexível e ágil tecnologicamente falando, `a formação de indivíduos capazes de, com rapidez, originalidade e eficiência, adaptarem-se às necessidades de cada momento, com visão crítica do meio no qual estarão atuando e com ciência da sua própria responsabilidade, não apenas como profissionais, mas também como cidadãos. (VASCONCELOS, 2000, p. 26).

Junto a esta formação cidadã, concordamos com Marques (2015), quando este afirma que o professor universitário (em especial) deverá constituir-se a partir de virtudes aliadas a todo educador de qualquer esfera, pois, ao formar indivíduos pela prática, ele formará sujeitos aptos a promoverem as mudanças necessárias e tão esperadas pelas sociedades.

Uma outra pergunta que indagamos aos nossos entrevistados foi: Se fosse possível melhorar o Ensino Remoto oferecido pela IES quais ações seriam? A nuvem de palavras número 02 foi formada pelos seguintes vocábulos:

Figura 2: Nuvem de Palavras 02

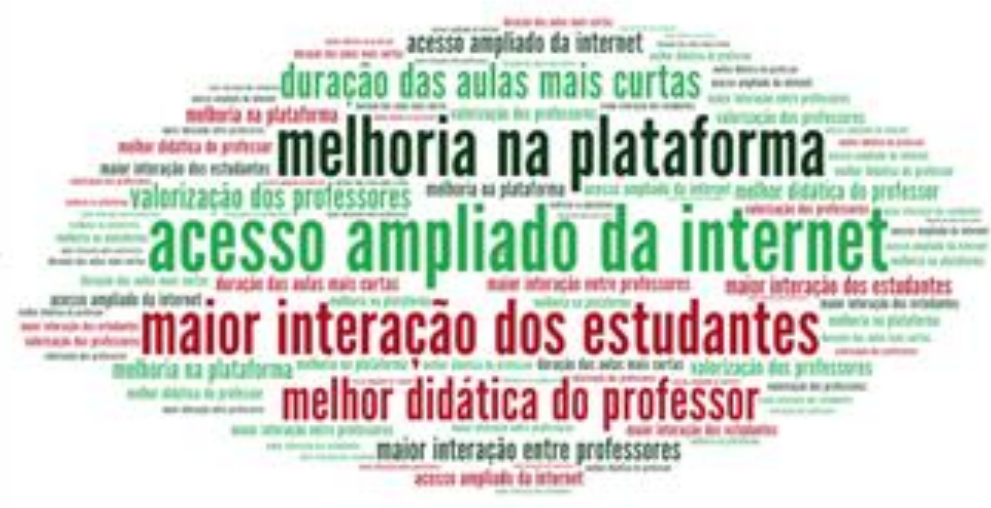

Fonte: Os autores, a partir dos dados da pesquisa.

Na segunda imagem, destacamos as seguintes expressões constituídas nas respostas do questionário e sua respectiva frequência: "acesso ampliado da internet" (197 vezes), "maior interação dos estudantes" (184 vezes), "melhoria da plataforma" (137 vezes), melhor didática do professor" (117 vezes) e "duração das aulas mais curtas" (116 vezes). 
Nas três primeiras, encontramos questões concernentes à apropriação do capital tecnológico, já na segunda temos um olhar para os recursos humanos envolvidos (professores e alunos).

Sabemos que o acesso ampliado à internet ainda é uma defasagem de âmbito nacional. A disponibilização livre necessita de recursos e financiamentos de ordem pública e privada a ser constituído a partir de projetos e programas de cooperação, uma vez que a organização das redes em nível nacional implica muito mais que aspectos técnicos.

O ensejo em uma "maior interação dos estudantes "relatado pelos docentes nos mostram que "a educação também compõe o atual cenário de mudanças implicadas com a alteração das relações com o saber e a organização em rede presentes na cultura digital" (ASSIS, 2013, p. 55), uma vez que ação interativa constitui elemento fundamental nas práticas pedagógicas no período de Ensino Remoto.

A essa interação, focalizamos também a questão da "didática do professor", uma vez que as duas relações se constituem de maneira indissociável, pois "o professor deve [...] pensar de modo ao mesmo tempo "global" e "local". Há de preparar os seus alunos para uma sociedade globalizada" (CHARLOT, 2013b, p. 100) e mediar o processo de apropriação da cultura digital, convertendo-a em uma cultura mais elaborada para o aluno.

Por fim, escolhemos outro questionamento muito rico nas respostas dadas pelos entrevistados: Qual(is) aprendizado(s) pode considerar relevante em sua prática docente no Ensino Remoto Emergencial (ERE)?

Figura 3: Nuvem de Palavras 03

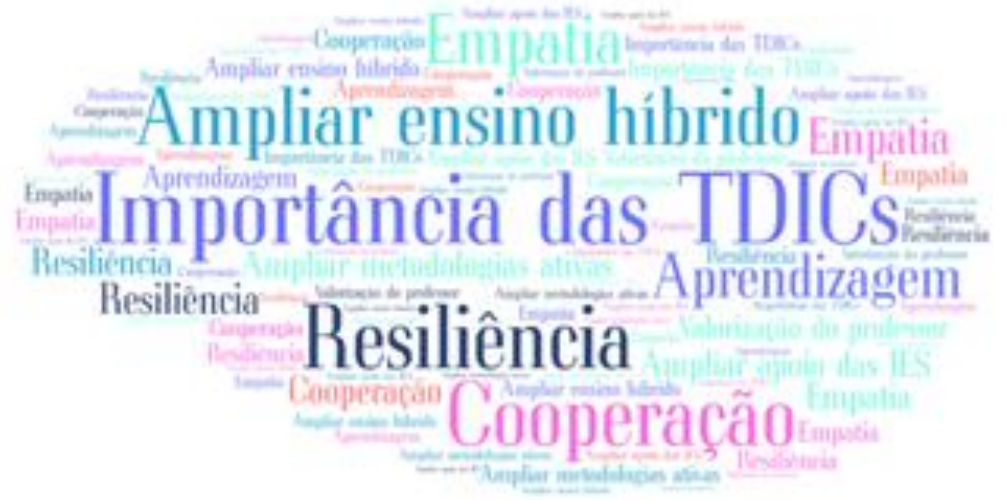

Fonte: Os autores, a partir dos dados da pesquisa. 
Das respostas em evidência destacamos a seguinte frequência: "importância das TDICs" (82 vezes), "ampliar ensino híbrido" (60 vezes), "Resiliência" (45 vezes), "Cooperação" (44 vezes), "Aprendizagem" (44 vezes), e "Empatia" (43 vezes), sendo que estas quatro últimas, constituem adjetivos fundamentais para um processo de aprendizagem focado na interação entre docentes e discentes, no processo de autonomia dos alunos e na mediação do professor.

Nesse sentido compreendemos que "atualmente o ensino se converteu em um trabalho coletivo necessário e imprescindível para melhorar o processo de trabalho dos professores, a organização das instituições educacionais e a aprendizagem dos alunos" (IMBERNÓN, 2010, p. 64), pois o trabalho de cooperação entre esse trinômio melhora e corrobora para o aumento dos índices de satisfação da aprendizagem.

Fica claro para todos nós que a emergência do ensino híbrido e a importância das Tecnologias Digitais de Informação e Comunicação que por anos foram taxadas grandes antagonistas das práticas educativas, hoje, tornam-se os maiores aliados deste processo que, ao fim (ou ao reducionismo) da Pandemia estarão presentes nos mais diversos espaços de ensino.

\section{CONSIDERAÇÕES FINAIS}

A Pandemia da COVID-19 reforçou a necessidade de Políticas Públicas para a implementação de TDICs nas Universidades, fato que também nos impulsionou a proposição desta pesquisa. O ERE desencadeou muitas discussões sobre a práticas pedagógica ofertada nas IES, e mesmo o mundo vivendo o auge da conectividade, muito se tem a falar e fazer em prol da qualidade do ensino e aprendizagem com utilização de tecnologias.

De um lado observamos que os meios digitais, mesmo fazendo parte do cotidiano dos indivíduos, ainda são pouco explorados no meio educacional, por outro lado, observamos a fragilidade da formação dos professores no Ensino Superior Brasileiro e a ineficácia do letramento digital entre os estudantes.

A emergencialidade não se propõem apenas em tempos de Pandemia, pois a que se pensar que o uso das TDICs e do Ensino Híbrido nas Universidades é um caminho sem volta. Tanto professores como estudantes, na pós Pandemia certamente desejaram que as tecnologias não sejam mais excluídas de suas vidas educacionais. A mudança é inevitável visto que o mundo está em movimento e a educação não pode ser obstante a tais acontecimentos.

Refletir sobre os discursos gerados pelos professores em atuação durante o período pandêmico, proporcionou-nos uma ampliação das questões que envolvem a docência no 
Ensino Superior presencial permitindo que a questão da virtualidade ou do hibridismo educacional possam dar espaço ao debate e à reflexões profícuas, uma vez que essa nova forma de trabalho docente permanecerá após a Pandemia.

\section{REFERÊNCIAS}

ANTUNES, Fernanda Regina et. al. Motivação de alunos de cursos presenciais para o uso de tecnologias digitais em disciplinas on-line. Revista Gaúcha de Enfermagem. Porto Alegre, v. 41. 2020. Disponível em:<https://bit.ly/2Y0ylDU>. Acesso: ago-2020.

ASSIS, Alessandra S. Didática, o Ensino na Licenciatura e as Tecnologias da Informação e da Comunicação. In: D’ÁVILA, C; VEIGA, I. P. A. (Orgs.). Didática e Docência na Educação Superior: implicações para a formação de professores. 1. ed. 1. reimp. Campinas (SP): Papirus, 2013. (Coleção Magistério: Formação e Trabalho Pedagógico).

BACICH, Lilian; MORAN, José Manuel. (Orgs.). Metodologias Ativas para uma Educação Inovadora: uma abordagem teórico-prática. Porto Alegre: Penso, 2018.

BAKHTIN, Mikhail. Para uma Filosofia do Ato Responsável. Tradução: Valdemir Miotello e Carlos Alberto Faraco. 2. ed. São Carlos (SP): Pedro \& João Editores, 2012.

BARDIN, Laurence. Análise de Conteúdo. Tradução: Luís Antero Reto e Augusto Pinheiro. 1. ed. 3. reimp. São Paulo: Edições 70, 2016.

BRASIL. Censo da Educação Superior 2018: notas e estatísticas. Brasília (DF): INEP/ MEC, 2019.

BRASIL. Portaria n. 544, de 16 de julho de 2020. Dispõe sobre a substituição das aulas presenciais por aulas em meios digitais, enquanto durar a situação de Pandemia do novo coronavírus-COVID-19. Brasília: MEC, 2020. Disponível em: < https://bit.ly/3ao6hiU>. Acesso: ago-2020.

BRASIL. Portaria $\mathbf{n}^{a}$ 343, de 17 março de 2020. Dispõe sobre a substituição das aulas presenciais por aulas em meios digitais, enquanto durar a situação de Pandemia do novo coronavírus-COVID-19. Brasília: MEC, 2020. Disponível em: 〈https://bit.ly/345bzP5>. Acesso: ago-2020.

CHARAUDEAU, Patrick. Linguagem e Discurso: modos de organização. Tradução: Ângela M. S. Corrêa e Ida Lúcia Machado. 2. ed. São Paulo: Contexto, 2016. 
CHARLOT, Bernard. A Mistificação Pedagógica: realidades sociais e processos ideológicos na teoria da educação. Tradução: Maria José A. Ferreira. 1. ed. rev. amp. São Paulo: Cortez, 2013a. (Coleção Docência em Formação: Saberes Pedagógicos).

CHARLOT, Bernard. Da Relação com o Saber às Práticas Educativas. São Paulo: Cortez, 2013b. (Coleção Docência em Formação: Saberes Pedagógicos).

CLARK, Katerina; HOLQUIST, Michael. Mikhail Bakhtin. Tradução: J. Guinsburg. São Paulo: Perspectiva, 2008.

CÓRICA, José Luis. Resistencia docente al cambio: Caracterización y estrategias para un problema no resuelto. RIED - Revista Iberamericana de Educación a Distancia. Madrid, v. 23, n. 2, p. 255-272. 2020.

DIAS, Guilherme Ataíde; ANJOS, Renata L. dos; RODRIGUES, Adriana A. Os Princípios FAIR: viabilizando o reuso de dados científicos. In: DIAS, G. A; OLIVEIRA, B. M. J. F. Dados Científicos: perspectivas e desafios. João Pessoa (PB): Editora da UFPB, 2019. Disponível em: <https://bit.ly/31BqAyD>. Acesso: agosto de 2020.

DOMINICK, Rejany dos S; ALVES, Walcéa B. Inclusão Digital e Inovação Pedagógica: Diálogo Necessário. RIAEE - Revista Ibero-Americana de Estudos em Educação. Araraquara (SP), v. 13, n. esp. 2, p. 1334-1358, set. 2018.

IMBERNÓN, Francisco. Formação Continuada de Professores. Tradução: Juliana S. Padilha. Porto Alegre: Artmed, 2010.

JOYE, Cassandra R; MOREIRA, Marília M; ROCHA, Sinara Socorro D. Educação a Distância ou Atividade Educacional Remota Emergencial: em busca do elo perdido da educação escolar em tempo de COVID-19. Reserach, Society and Development. Itajubá (MG), v, 9, n.07, p. 1-29. 2020

MAINGUENEAU, Dominique. Discurso e Análise do Discurso. Tradução: Sírio Possenti. São Paulo: Parábola Editorial, 2015. (Coleção Língua[gem], v. 64).

MAINGUENEAU, Dominique. Doze Conceitos em Análise do Discurso. Tradução: Adail Sobral et. al. São Paulo: Parábola Editorial, 2010. (Coleção Língua[gem], v. 41).

MARQUES, Heitor Romero. Metodologia do Ensino Superior. 5. ed. rev. amp. Campo Grande: UCDB, 2015.

MORAN, José Manuel. A contribuição das tecnologias para uma educação inovadora. Contrapontos. Itajaí (SC), v. 04, n 2, p. 347-356, mai-ago. 2004. 
MOREIRA, José Antônio M.; HENRIQUES, Suzana; BARROS, Daniela. Transitando de um Ensino Remoto Emergencial para uma educação digital em rede, em tempos de Pandemia. Dialogia. São Paulo, n. 34, p. 351-364. jan-abr. 2020.

PIMENTA, Selma G; ANASTASIOU, Léa das Graças C. Docência no Ensino Superior. 5. ed. São Paulo: Cortez, 2014. (Coleção Docência em Formação. Série Ensino Superior).

PRAIS, Jacqueline Lidiane de S; ROSA, Vanderley F. Nuvem de Palavras e Mapa Conceitual: estratégias e recursos tecnológicos na prática pedagógica. Nuances: estudos sobre Educação. Presidente Prudente (SP), v, 28, n. 01, p. 201-219, jan-abr. 2017.

REVUELTA, Maria José C. et. al. Potencialidades de las TIC y su papel fomentando la creatividad: percepciones del professorado. RIED - Revista Iberamericana de Educación a Distancia. Madrid. V, 23, n. 2, p. 287-306. 2020.

SILVA, Ângela C. Educação e Tecnologia: entre o discurso e a prática. Ensaio. Rio de Janeiro, v. 19, n. 72, p.527-554, jul-set. 2011.

SOARES, Magda. Linguagem e Escola: uma perspectiva social. 17. ed. São Paulo: Ática, 2017.

UNESCO. Metade dos Alunos fora da Escola não têm Computador em Casa. 2020. Disponível em: < https://bit.ly/3kKt39t >. Acesso: ago-2020.

VASCONCELOS, Maria Lúcia C. M. A Formação do Professor do Ensino Superior. 2. ed. Pioneira. São Paulo, 2000.

VASCONCELOS, Maria Lúcia C. M. A Internet e as Novas Tecnologias como Recursos Didático-Pedagógicos: entre o uso e a perplexidade. Estudos Semióticos. São Paulo, v. 15, n 02, p. 63-73, dez. 2019.

VOLÓCHINOV, Valentin. Marxismo e Filosofia da Linguagem. Trad, Sheila Grillo e Ekaterina Vólkova Américo. São Paulo: Editora 34, 2017.

\footnotetext{
* Alan Silus é Professor Universitário, Procurador Institucional e Assessor Cultural. Na UFMS é membro do Grupo de Estudos e Pesquisa em Formação de Professores (GEPFORP/ FAED) e do Grupo de Pesquisa em Linguagem, Educação e Infância/ Teoria Histórico-Cultural (GEPLEI-THC/ CPTL). Na UEMS é membro do Núcleo de Estudos Bakhtinianos (NEBA) e do Centro de Pesquisa, Ensino e Extensão em Educação, Linguagem, Memória e Identidade (CELMI).
}

** Angelita Leal de Castro Fonseca é Licenciada em Ciências Biológicas, Especialista em Educação Ambiental e Mestre em Ensino de Ciências. Especializações em em A Moderna Educação: metodologias, 
tendências e foco no aluno pela Pontifícia Universidade Católica do Rio Grande do Sul (PUCRS) e cursa Especialização em Microbiologia Avançada pelo Centro Universitário UNIGRAN Capital onde é Docente e Assessora de Metodologias de Ensino. Possui experiência em Ensino Superior atuando nas seguintes áreas: Microbiologia, Biossegurança, Citologia, Histologia, Metodologia Científica Metodologias Ativas de Aprendizagem, Elaboração de Materiais Didáticos e Sequências Didáticas. Membro do Grupo de Pesquisa Práticas Educativas Inclusivas - Reconstruindo a Escola (GEPPEI-RE/ UFMS).

*** Djanires Lageano Neto de Jesus possui Graduação em Turismo, Administração e Pedagogia, Especialização em Gestão Empreendedora de Negócios, Mestrado e Doutorado em Geografia. É Docente da Universidade Estadual de Mato Grosso do Sul - UEMS, Unidade Universitária de Campo Grande, membro do Conselho Estadual de Educação de Mato Grosso do Sul e Avaliador Ad Hoc para autorização e reconhecimentos de cursos superiores do INEP/ MEC. Possui experiência em Turismo, Gestão e Educação, atuando nos seguintes temas: Educação, Turismo, Administração, Planejamento e Gestão de Oportunidades, Gestão de Pessoas e Coaching, Empreendedorismo, Metodologias Ativas e Planejamento Estratégico. 